\title{
Anti and Promelanogenic Activity of Oxidized and Non- oxidized Piper betle Leaf Extract on B16-F1 Melanoma Cells
}

\author{
H. E. CHIU, V. J. WU1 ${ }^{1}$, Y. C. SHEN², K. VENKATAKRISHNAN ${ }^{1}$ AND C. N. WANG ${ }^{1 *}$
}

Department of Chinese Medicine, Taichung Hospital Ministry of Health and Well-being, Taichung, Taiwan, ${ }^{1}$ School of Nutrition, Chung Shan Medical University, 110, Sec. 1, Jianguo North Road, Taichung City, Taiwan, ${ }^{2}$ School of Health Diet and Industry Management, Chung Shan Medical University, 110, Sec. 1, Jianguo North Road, Taichung City, Taiwan, ROC

Chiu et al.: Anti and pro-melanogenic effect of Piper betle

\begin{abstract}
The current study was attempted to investigate the effect of melanogenesis and the mechanism behind both hypo and hyperpigmentation by oxidized and non-oxidized Piper betle extracts and on B16F1 melanoma cells. Supplementation with oxidized or non-oxidized Piper betle extracts did not show any significant cytotoxicity (90\% intact cells) in B16F1 melanoma cells. However, the activity of tyrosinase and the levels of lipid peroxidation product (thiobarbituric acid reactive substances), and melanin secretion was significantly decreased with improved antioxidant status after $48 \mathrm{~h}$ of incubation with increasing dose (25/35/50 $\mu \mathrm{g} / \mathrm{ml}$ ) of non-oxidized Piper betle extract in B16F1 melanoma cells. However, slightly decreased antioxidant status with increased melanin content was observed at $72 \mathrm{~h}$ (Piper betle extract). The above results indicated that as the duration increased the effect of non-oxidized Piper betle extract on melanin synthesis started to decline. In addition, when oxidized Piper betle extract $(35 / 50 \mu \mathrm{g} / \mathrm{ml})$ was incubated with B16F1 cells hyperpigmentation was noted within $48 \mathrm{~h}$ by enhancing the levels of thiobarbituric acid reactive substances $(35 \%)$ and melanin secretion as well as tyrosinase activity $(\max$ at $72 \mathrm{~h}$ ) with lowered tyrosinase inhibitory activity. Taking together that oxidized Piper betle extract might be the reason for the hyperpigmentation and might contribute to various dermal disorders and thus non-oxidized Piper betle extract to be recommended for treating various dermal disorders.
\end{abstract}

Key words: Hyperpigmentation, Piper betle, tyrosinase, melanin, antioxidant status

In humans, melanin pigmentation is one of the vital defense mechanisms against harmful UV rays from sunlight. However, excessive or lesser pigmentation (hyper or hypopigmentation) can result in numerous dermal disorders like melanoma, melasma, vitiligo, solar lentigo and leukomelanosis ${ }^{[1]}$. Melanin synthesis was regulated by several factors, primarily by the alteration or modulation of the expression pattern of tyrosinase (copper-containing monooxygenase enzyme), a key regulatory enzyme involved in melanin synthesis by catalyzing the conversion of L-tyrosine into 3,4-dihydroxyphenylalanine (L-DOPA) and L-DOPA to dopaquinone. Hence, it is a crucial factor for both hyper and hypopigmentation ${ }^{[2,3]}$. Both hyperpigmentation and hypopigmentation are related to melanin biosynthesis (melanogenesis) and hence a drug, which can regulate the formation of melanin would be essential for treating various pigment related disorders. Ample amount of studies demonstrated that

*Address for correspondence

E-mail: wckjff@gmail.com

September-October 2019 plant extracts or natural products (polyphenols) with a higher antioxidant capacity is highly recommended for alleviating derma or pigmentation disorders without or less adverse effects ${ }^{[4,5]}$.

Piper betle Linn. is a perennial climbing plant with heart-shaped leaves, which belongs to the family Piperaceae. Its leaves are usually green or pale yellow and is used as a major component of betel quid (paan) by wrapping up with areca nut, tobacco, and lime $^{[6,7]}$. In Asian countries (China, Taiwan, India, Vietnam, Indonesia, and Thailand), $P$. betle leaves (medicinal spice) were traditionally recommended

This is an open access article distributed under the terms of the Creative Commons Attribution-NonCommercial-ShareAlike 3.0 License, which allows others to remix, tweak, and build upon the work non-commercially, as long as the author is credited and the new creations are licensed under the identical terms

Accepted 04 August 2019

Revised 13 May 2019

Received 01 January 2019

Indian J Pharm Sci 2019;81(5):868-875 
for indigestion, constipation, and cough as well as to alleviate bad breath ${ }^{[8]}$. It has been accounted for an array of pharmacological properties like antioxidant, immunomodulatory, antibacterial, antidiabetic as well as act as dermaprotective, radioprotective, gastroprotective and hepatoprotective agent ${ }^{[9-11]}$. The major components of $P$. betle leaves/oil are polyphenols, terpenes, alkaloids, steroids, saponins, tannins, and flavonoids out of which allyl pyrocatechol, eugenol, and chavibetol are the major active phytoconstituents. $P$. betle leaves are also rich in vitamins, minerals, and essential amino acids, particularly tyrosine ${ }^{[12,13]}$.

In Taiwan, $P$. betle leaves (steamed) are used as a hypopigmenting (bleaching) agent ${ }^{[1]}$. Nevertheless, many surveys have documented that usage of $P$. betle as a bleaching agent for few days shows effective hypopigmentation, but long-term use may lead to hyperpigmentation and subsequently results in severe facial leukomealnosis ${ }^{[14-16]}$. Therefore, to clarify the exact reason behind the dual activity (hypo and hyperpigmentation) of $P$. betle leaves, normal $P$. betle leaves and oxidized polyphenol extract of $P$. betle were used on $\mathrm{B} 16 \mathrm{~F} 1$ melanoma cells (mimics human melanoma cells) to investigate its anti or promelanogenesis property with different doses and treatment durations $(24,48,72 \mathrm{~h})$.

\section{MATERIALS AND METHODS}

\section{$P$. betle leaves extract preparation:}

$P$. betle leaves were bought from the local market of Taimali, Taitung, Taiwan, which were authenticated in the Chung Shan Medical University, Taiwan. Fresh leaves (100 g) were cut into small pieces using a blender (coarse powder) and macerated in $80 \%$ aqueous acetone solution $(300 \mathrm{ml})$ and incubated at room temperature for $1 \mathrm{~d}$. Then the crude extract was filtered through Whatman No. 4 filter paper. The remaining residues were also extracted by the procedure mentioned above. The filtrates obtained were combined and concentrated in vaccuo, freeze-dried (lyophilized) with liquid nitrogen, designated as nonoxidized $P$. betle extract (PBE) and was stored at $-20^{\circ}$ (yield $12.5 \%$, w/w). Whereas, oxidized $P$. betle leaves extract (OPBE) was prepared by exposing the extract to open air and sunlight to undergo auto-oxidation for $3 \mathrm{~d}$ followed by the same procedure as indicated above for PBE. The final yield of OPBE is $7.2 \%, \mathrm{w} / \mathrm{w}$. Then, the PBE and OPBE were dissolved in dimethyl sulfoxide (DMSO) final concentration $<0.02 \%$ with culture medium, Dulbecco's modified Eagles medium (DMEM) and diluted to appropriate concentrations $(25,35$ and $50 \mu \mathrm{g} / \mathrm{ml})$.

\section{Cell culture studies:}

B16F1 murine melanoma cells were purchased from the American Type Culture Collection (ATCC; MD, USA). Melanoma cells were grown in DMEM and supplemented with $1 \%$ penicillin, $1 \%$ streptomycin, $2 \mathrm{mM}$ L-glutamine and $10 \%$ fetal bovine serum were incubated at $37^{\circ}$ in a humidified atmosphere of $5 \%$ $\mathrm{CO}_{2}$.

\section{Morphological examination:}

The normal B16F1 melanoma cells (without the addition of samples) and cells treated with different concentrations of PBE and OPBE were observed under a normal phase contrast microscope (Nikon Eclipse T 100, Tokyo, Japan) and photographed using a digital camera to assess any morphological changes.

\section{Cell viability assay:}

The B16F1 melanoma cell viability was evaluated using 3-(4,5-dimethylthiazol-2-yl)-2,5-diphenyltetrazolium bromide (MTT) dye. Melanoma cells $\left(1 \times 10^{5} / \mathrm{ml}\right)$ were added to each well of the 96-well plate and incubated overnight at room temperature. Next day new DMEM with nutrient broth (media) were substituted by replacing the old media and mixed with increasing concentrations of PBE or OPBE for $24 \mathrm{~h}$ at $37^{\circ}$. After the addition of samples, MTT was added $(100 \mu \mathrm{l})$ to each well and incubated at $37^{\circ}$ for $30 \mathrm{~min}$, and finally, DMSO was added to dissolve the formazan crystals formed. The optical density was quantified at $560 \mathrm{~nm}$ using UV/Vis spectrophotometer.

\section{Protein content, antioxidant and thiobarbituric acid reactive substances (TBARS) levels:}

The protein content, antioxidant efficiency, and lipid peroxidation products, TBARS were quantified by BCA protein (Sigma; MO, USA), antioxidant and TBARS assay kit, respectively (Cayman Chemical; MI, USA) based on supplier's instructions.

\section{Assay of cellular tyrosinase activity:}

Tyrosinase activity was assessed as described previously by Kojima et al..$^{[17]}$. The B16F1 melanoma cells were seeded in a Petri dish with or without samples (PBE or OPBE) and incubated for $24 \mathrm{~h}$. Then, the cells were washed with phosphate buffered saline (PBS; pH 7.4) and disrupted with a PBS solution containing $1 \%$ Triton 
$\mathrm{X}-100$. Afterwards, all cells were lysed in a sonicator, and the lysates were centrifuged at $10000 \times \mathrm{g}$ for $10 \mathrm{~min}$. Only the supernatant was used for the further process. The supernatant $(0.5 \mathrm{ml})$ was added into each well of a 96-well plate containing approximately $50 \mu \mathrm{g}$ protein, $2.5 \mathrm{mM}$ L-DOPA, and 0.1 M PBS. After incubation at $37^{\circ}$ for $1 \mathrm{~h}$, the absorbance was measured at $475 \mathrm{~nm}$ using microplate reader for every $5 \mathrm{~min}$. The specific activity of tyrosinase was expressed as units per liter (U/l) from $\Delta E / \mathrm{min}$ at $475 \mathrm{~nm}$.

\section{Assay of cell-free tyrosinase inhibition assay:}

Cell-free tyrosinase activity was assayed as DOPA oxidase activity by the method of Yagi et al. ${ }^{[18]}$ with a slight modification. Briefly, $70 \mu \mathrm{l}$ of $0.1 \mathrm{M}$ PBS $(\mathrm{pH}$ 6.8) was added with different concentrations of PBE or OPBE and $20 \mu \mathrm{l}$ of $10 \mu \mathrm{g} / \mathrm{ml}$ mushroom tyrosinase in a 96-well plate, $10 \mu 1$ of $10 \mathrm{mM}$ L-DOPA was added to this mixture. The amount of dopachrome produced in the reaction mixture was determined against a blank, and the absorbance was measured at $475 \mathrm{~nm}$ using a microplate reader. Percent inhibition of tyrosinase was calculated using the formula, $\%$ inhibition $=(\mathrm{A}-\mathrm{B}) / \mathrm{A} \times 100$, where $\mathrm{A}=$ absorbance at $475 \mathrm{~nm}$ without test sample, $B=$ absorbance at $475 \mathrm{~nm}$ with the test sample.

\section{Melanin content:}

The melanin content of the cultured B16F1 melanoma cells was determined by the method of Rosenthal et al. ${ }^{[19]}$ with minor alterations. Melanoma cells were added to PBS solution mixed with ethyl alcohol and diethyl ether (3:1) with different concentration of PBE or OPBE and centrifuged at $10000 \times \mathrm{g}$. Then the supernatant was discarded and the remaining cell pellet was resuspended in $1 \mathrm{ml}$ of $1 \mathrm{~N} \mathrm{NaOH}$ or $\mathrm{KOH}$. Finally, the absorbance of each well was measured using an ELISA reader at $400 \mathrm{~nm}$. The amount of melanin (cellular) was quantified based on the protein content of the samples.

\section{Statistical analysis:}

Data are expressed as mean \pm standard deviation (SD). The experiments were conducted in triplicate. Significant differences in this study between DMSO and test compound doses were determined using one-way ANOVA followed by Tukey post-hoc test for multiple comparisons using SPSS software (21.0; IBM, USA). $\mathrm{P}<0.05$ were considered as statistically significant.

\section{RESULTS AND DISCUSSION}

The phase contrast microscope was employed to assess any morphological changes in melanoma cells upon exposure with PBE or OPBE (fig. 1). The morphology of $\mathrm{B} 16 \mathrm{~F} 1$ melanoma cells (without addition of DMSO or sample) displayed normal architecture with spherical shaped cells at different durations. While, B16F10 cells treated with $50 \mu \mathrm{g} / \mathrm{ml}$ of PBE or OPBE
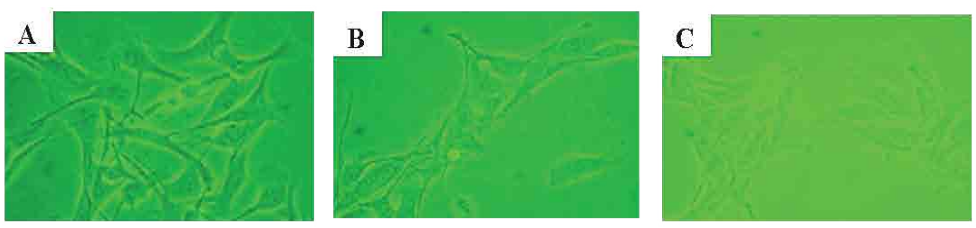

$24 \mathrm{~h}$
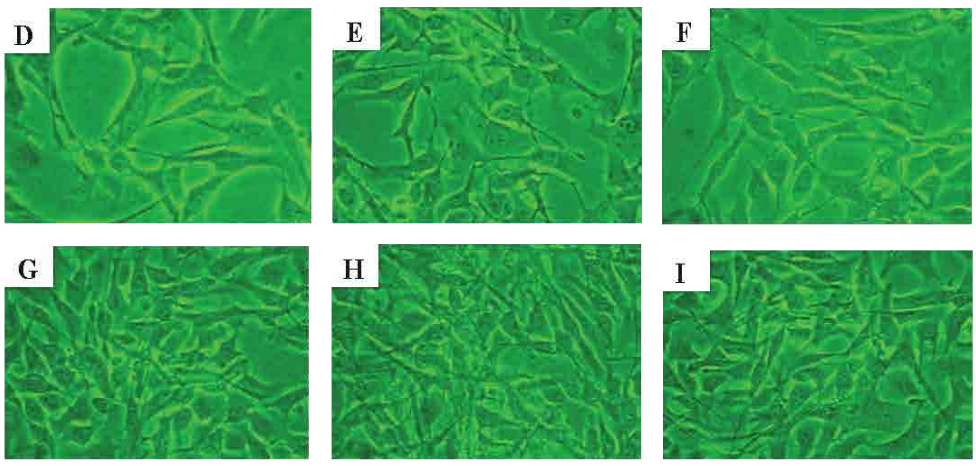

$50 \mu \mathrm{g} / \mathrm{ml}$ of PBE
$50 \mu \mathrm{g} / \mathrm{ml}$ of

OPBE

Fig. 1: Microscopic examination of normal B16F1 cells exposed to DMSO, or PBE or OPBE

Microscopic examination of normal B16F1 cells treated with DMSO or $50 \mu \mathrm{g} / \mathrm{ml}$ of PBE or OBPE and exposed for (A-C) $24 \mathrm{~h}$ or for (D-F) $48 \mathrm{~h}$ or for (G-I) $72 \mathrm{~h}$ (200X) 
for different duration $(24,48$, and $72 \mathrm{~h})$ did not portray any significant morphological changes (no signs of flattened or distorted nucleoli), but the cell count (density) was significantly improved with time in a dose-dependent manner.

The B16F1 melanoma cell viability was determined by the MTT assay method (fig. 2). The PBE (fig. 2A) or OPBE (fig. 2B)-treated cells at different concentration $(25,35$ and $50 \mu \mathrm{g} / \mathrm{ml})$ and duration $(24,48$ and $72 \mathrm{~h})$ showed no potential toxicity or cell count as compared to DMSO-treated control cells. Even when incubated at $50 \mu \mathrm{g} / \mathrm{ml}$ for $72 \mathrm{~h} 90 \%$ of cells survived indicating the non-cytotoxic nature of the extracts

The protein content (fig. 3) was greatly increased as the time of incubation increased from 24 to 48 and $72 \mathrm{~h}$, but no significant changes were observed between the different concentration of both PBE (fig. 3A) or OPBE (fig. 3B) at different time duration. Thus proving that PBE or OPBE would not alter either growth pattern or

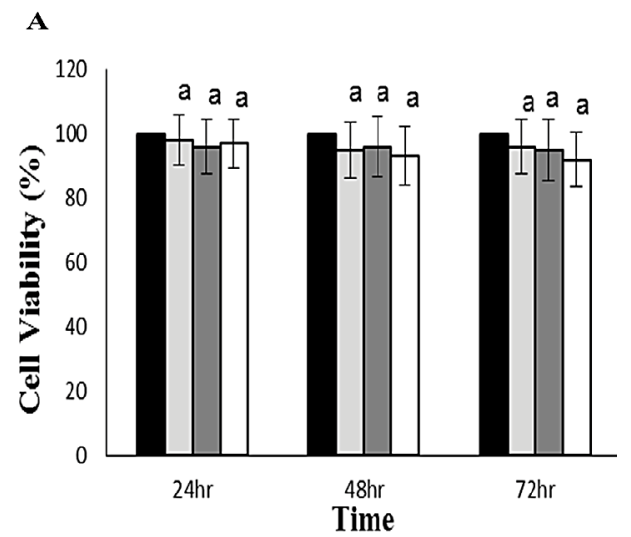

normal metabolism by inhibiting protein synthesis or remodulation.

Fig. 4 illustrates the changes in oxidative indices like total antioxidant efficiency as well as lipid peroxidation products such as TBARS in PBE- or OPBE-treated B16F1 melanoma cells. The levels of antioxidant efficiency were exponentially increased in PBE (48 $\mathrm{h}$ and $72 \mathrm{~h}$ ), and OPBE ( $72 \mathrm{~h}$ ) treated cells at the concentration of 35 , and $50 \mu \mathrm{g} / \mathrm{ml}$ in comparison to DMSO exposed control cells. Whereas, the levels of TBARS were concomitantly reduced upon addition of 35 and $50 \mu \mathrm{g} / \mathrm{ml}$ PBE (72 h), while no marked changes were noted in cells exposed to OPBE or DMSO alone.

Treatment with PBE significantly reduced tyrosinase activity (fig. 5A) with enhanced tyrosinase inhibitory (fig. 5B) property in comparison with DMSO treated cells. Notably, $35 \mu \mathrm{g} / \mathrm{ml}$ of PBE showed the highest tyrosinase inhibition. Nonetheless, OPBE-treated cells showed increased tyrosinase activity (fig. 5C)

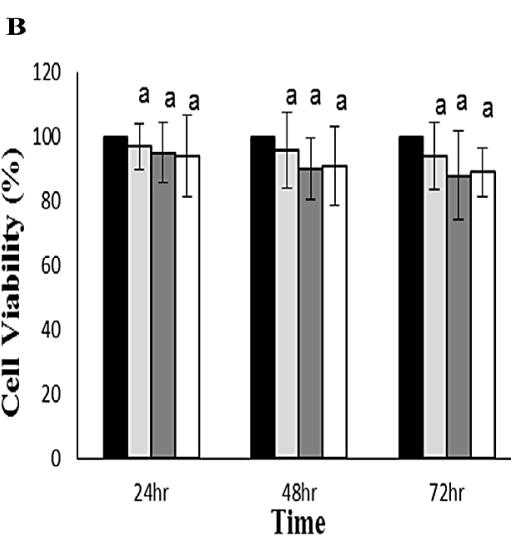

Fig. 2: Effect of $P B E$ and $O P B E$ on viability in $B 16 F 1$ cells with time Effect of (A) PBE and (B) OPBE on the viability in B16F1 cells at different times of incubation. Data expressed as means \pm SD. Bars bearing letters indicate significantly different from each group (p<0.05). ( $\square$ ) Control, ( $\square) 25 \mu \mathrm{g} / \mathrm{ml},(\square) 35 \mu \mathrm{g} / \mathrm{ml},(\square) 50 \mu \mathrm{g} / \mathrm{ml}$

A

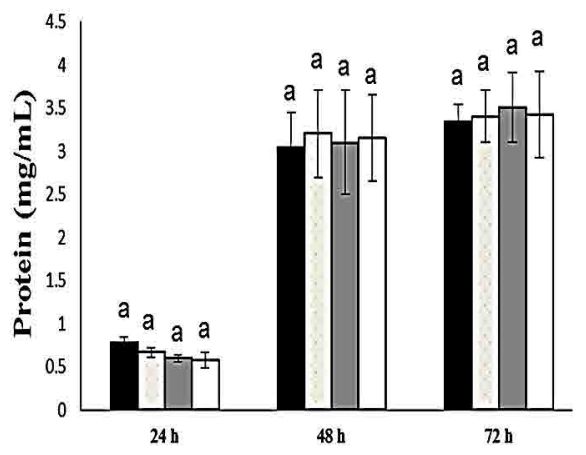

B

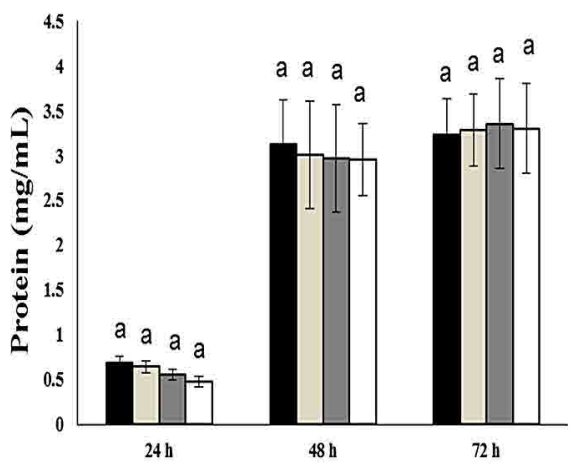

Fig. 3: Effect of PBE and OPBE on the protein contents of B16F1 cells with time Effect of (A) PBE and (B) OPBE on the protein contents of B16F1 cells after incubation for different periods. Data expressed as means \pm SD. Bar bearing letters were significantly different from each group (p<0.05). ( $\square$ ) Control, ( $\square) 25 \mu \mathrm{g} / \mathrm{ml},(\square) 35 \mu \mathrm{g} / \mathrm{ml},(\square)$ $50 \mu \mathrm{g} / \mathrm{ml}$ 
with lesser tyrosinase inhibitory (fig. 5D) activity in a manner similar to that observed in DMSO-treated cells. Both 35 and $50 \mu \mathrm{g} / \mathrm{ml}$ concentration of OPBE displayed better tyrosinase activity indicating its promelanogenic activity. In comparison to DMSO- treated cells, 35 and $50 \mu \mathrm{g}$ of PBE (fig. 6A) exerted least melanogenesis, which reflected in lower melanin content. Meanwhile, OPBE (fig. 6B) added cells showed maximum melanogenesis and greater melanin content, especially at the dose of $35 \mu \mathrm{g} / \mathrm{ml}$.
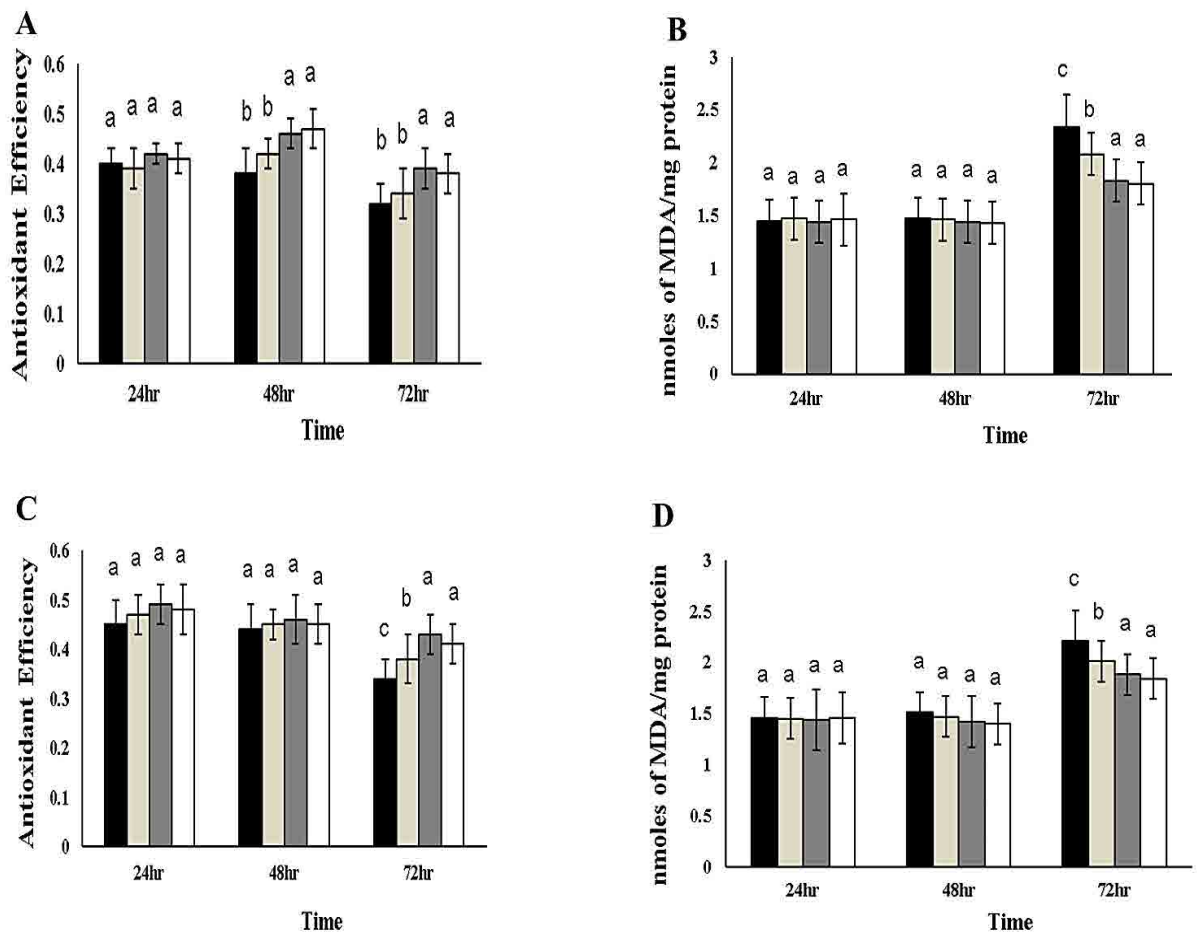

Fig. 4: Effect of PBE and OPBE on antioxidant activity and lipid peroxidation product in B16F1 cells with time Effect of (A) PBE and (C) OPBE on antioxidant activity and effect of (B) PBE and (D) OPBE on lipid peroxidation product, TBARS in $B 16 F 1$ cells, Data expressed as means \pm SD. Bars bearing different letters were significantly different from each group ( $<<0.05$ ). (घ) Control, ( $\square$ ) $25 \mu \mathrm{g} / \mathrm{ml},(\square) 35 \mu \mathrm{g} / \mathrm{ml}$, (口) $50 \mu \mathrm{g} / \mathrm{ml}$
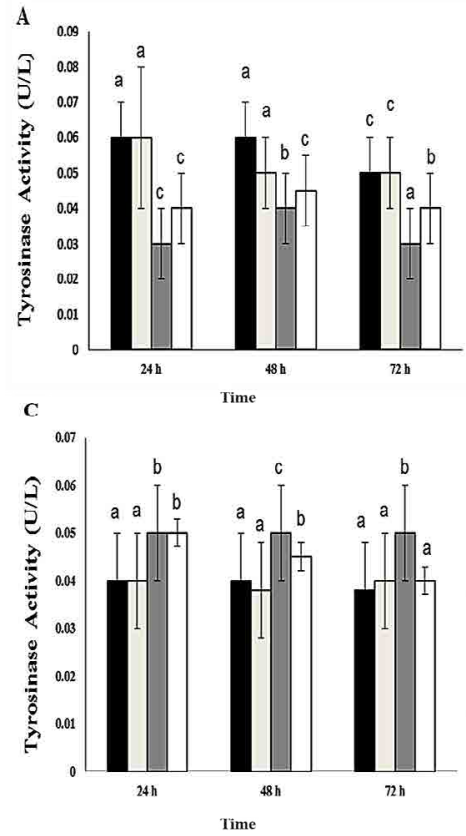

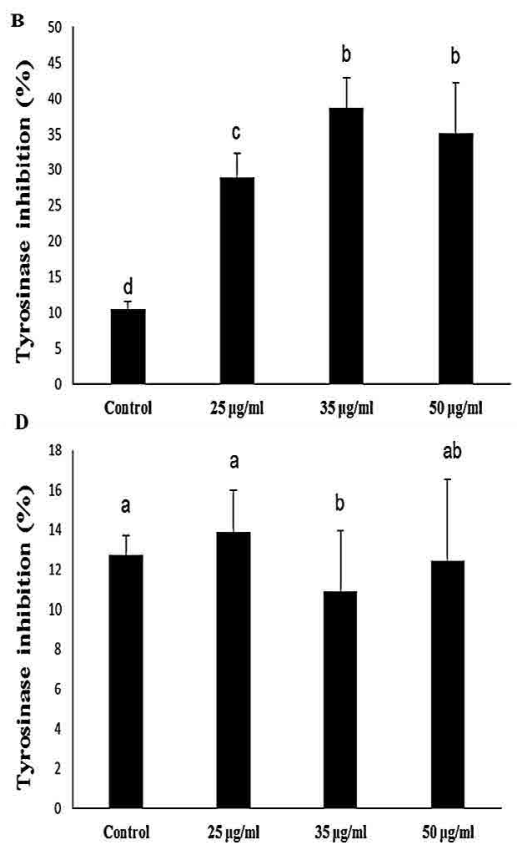

Fig. 5: Effect of PBE and OPBE on tyrosinase activity in mushroom tyrosinase in vitro model

Effect of (A) PBE and (C) OPBE on tyrosinase activity in B16F1 cells and effect of (B) PBE and (D) OPBE on tyrosinase inhibitory activity in mushroom tyrosinase in vitro model. Data are expressed as means \pm SD. Bar bearing different letters were significantly different from each group (p<0.05). (ø) Control, ( $\square) 25 \mu \mathrm{g} / \mathrm{ml},(\square) 35 \mu \mathrm{g} / \mathrm{ml},(\square) 50 \mu \mathrm{g} / \mathrm{ml}$ 

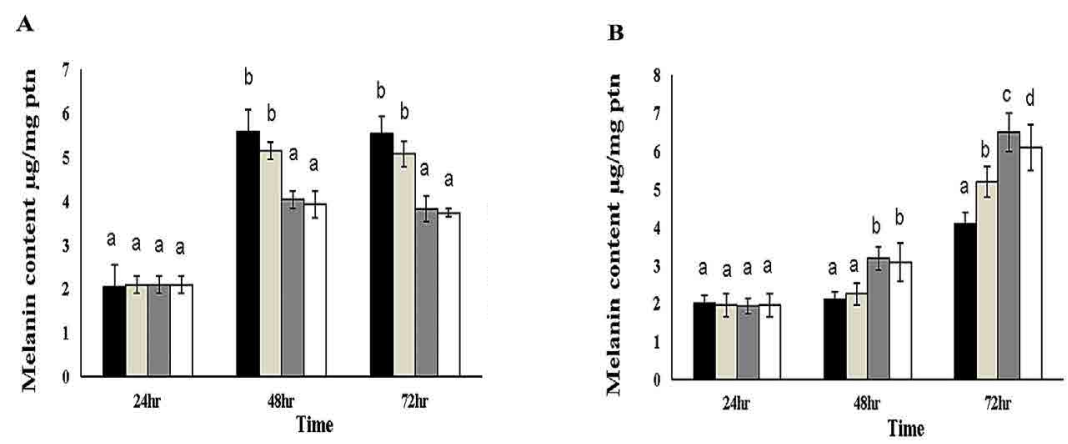

Fig. 6: Effect of PBE and OPBE on melanin content in B16F1 cells with time Effect of (A) PBE and (B) OPBE on melanin content in B16F1 cells at different periods of incubation. Data expressed as means \pm SD. Bar bearing different letters were significantly different from each group (p<0.05). (घ) Control, ( $\left.)^{2}\right) 25 \mu \mathrm{g} / \mathrm{ml},(\square) 35 \mu \mathrm{g} / \mathrm{ml}$, (口) $50 \mu \mathrm{g} / \mathrm{ml}$

$P$. betle leaves have been reported to exert both hypo and hyperpigmentation in different in vitro and in vivo model ${ }^{[14-16]}$. However, its mechanism or reason behind its dual activity was not explored. This study appeared to be the first study to explore the exact reason for both hypo, and hyperpigmentation property of $P$. betle leaves on B16F1 melanoma cell line by evaluating the morphological and biochemical changes in cell viability (cytotoxicity), protein contents, oxidative status, melanin contents, and tyrosinase activity. Moreover, in the present study, two different types of $P$. betle leaf extracts were utilized such as normal PBE, and auto-oxidized form of $P$. betle leaf extract (OPBE) were used.

The morphology of B16F1 melanoma cells treated with $50 \mu \mathrm{g} / \mathrm{ml}$ of PBE or OPBE for different durations (24, 48, and $72 \mathrm{~h})$ did not show any significant morphological changes, but the cell count (density) was significantly improved with time in a dose-dependent fashion. These results were in agreement with the results of Liu et al. ${ }^{[15]}$, who also demonstrated that $P$. betle did not induce any morphological changes at a lower concentration. Moreover, B16F1 melanoma cells treated with 25,35 and $50 \mu \mathrm{g} / \mathrm{ml}$ of PBE or OPBE for 24 , 48 , and $72 \mathrm{~h}$ depicted no potential toxicity as compared to DMSO-treated control cells. Even after $72 \mathrm{~h}$ exposure to $50 \mu \mathrm{g} / \mathrm{ml} 90 \%$ of cells survived which indicated that the extracts were not cytotoxic.

To support the morphological changes (dense cell), protein content also increased as the duration increased from 24 to $72 \mathrm{~h}$. Nevertheless, no considerable alteration was noted between different concentration of both PBE or OPBE after incubation for different periods. The above results indicated that both $\mathrm{PBE}$ and OPBE have no effect on growth pattern or metabolism through modulating protein synthesis. Likewise,
Bhattacharya et al..$^{[20]}$ and Mula et al..$^{[21]}$ reported that $P$. betle and its constituents were non-toxic to cell lines at a lower concentration, but exerted mild toxicity at higher concentration.

Few studies have reported that free radicals are implicated in excessive melanogenesis ${ }^{[22,23]}$. Hence, the oxidative status of $\mathrm{B} 16 \mathrm{~F} 1$ melanoma cells was investigated after treating with $\mathrm{PBE}$ and OPBE. Antioxidant efficiency of the B16F1 melanoma cells was increased with a significant decrease in the levels of TBARS in PBE-treated melanoma cells after $72 \mathrm{~h}$ exposure, at which time the protein levels increased. However, the antioxidant activity were considerably improved after cells treated with different concentration of OPBE at $72 \mathrm{~h}$, without any change in TBARS level. It has been demonstrated that $P$. betle leaves have considerable free radical quenching activity, owing to the presence of allyl pyrocatechol, phenols, and catechols ${ }^{[24]}$. Furthermore, Bhattacharya et al. ${ }^{[25]}$, highlighted that $P$. betle treatment could markedly alleviate excessive free radical generation and subsequently lowered the lipid peroxidation process due to enhanced superoxide dismutase activity with increased free radical quenching ability. Based on this outcome, it is possible to infer that PBE showed a better antioxidant capacity than OPBE due to the excessive oxidation process.

It has been hypothesized that excessive production of free radicals might activate microphthalmia-associated transcription factor (MITF) and thereby positively modulate the transcription of tyrosinase (tyrosinaserelated protein; TRP-1 and 2) and subsequent melanin synthesis ${ }^{[26,27]}$. Therefore, in the current study tyrosinase activity and melanin contents were assessed to testify the anti and promelanogenic activity of PBE and OPBE on B16F1 melanoma cells. Tyrosinase activity 
in melanoma cells and cell-free (using mushroom tyrosinase) tyrosinase inhibition property were assayed to measure the efficiency of PBE or OPBE on melanin synthesis.

Treatment with PBE significantly reduced the tyrosinase activity with enhanced tyrosinase inhibition. Particularly, $35 \mu \mathrm{g} / \mathrm{ml}$ of PBE showed better tyrosinase inhibition resulting in antimelanogenesis activity. $P$. betle extract inhibited tyrosinase activity owing to the presence of allyphenolic compound ${ }^{[16]}$. Moreover, it was speculated that $P$. betle leaves could act as competitive inhibitors of tyrosinase by blocking the binding of the substrate with the active site of tyrosinase. Recently, $P$. betle has been reported to be competitive inhibitors of copper and iron-containing enzymes $^{[28]}$. In case of OPBE, treated cells showed increased tyrosinase activity with decreased tyrosinase inhibitory property. Both 35 and $50 \mu \mathrm{g} / \mathrm{ml}$ concentration of OPBE displayed better tyrosinase activity indicating its pro-melanogenic activity. Tan and Chan ${ }^{[14]}$ indicated that the leaves of $P$. betle probably increased tyrosinase activity, but the mechanism was yet to be explored.

Finally, the melanin content was measured to check the effect of PBE or OPBE on melanin production. PBE-treated cells had the lowest melanogenesis activity, which reflected in the lower melanin content. While, OPBE-treated cells showed the highest melanogenesis activity, particularly at the dose of $35 \mu \mathrm{g} / \mathrm{ml}$. As indicated earlier, PBE inhibited melanogenesis, and OPBE promoted melanogenesis owing to the altered tyrosinase activity. Similarly, Liu and others ${ }^{[15]}$, observed that $P$. betle leaf extract could increase the melanin synthesis most probably due to different phytoconstituents, which might influence the expressions of TRP and tyrosine activity.

Therefore, PBE owing to its higher antioxidant capacity and different ratios of phytocomponents, might lower the expression of TRP and thus lower the tyrosinase activity and subsequently inhibit melanin production. Furthermore, OPBE presumably with a different proportion of phytocomponents might increase tyrosinase activity due to lesser antioxidant efficiency and eventually end up in excessive production of melanin. Few limitations of this experiment were not to examine the active components of PBE or OPBE to elucidate the precise mechanism for anti or pro melanogenic activities pertaining to signaling pathway related to MITF and TRP-1/2 expression as well as reducung the inducer-like UV light or $\alpha-\mathrm{MSH}$. The present study inferred that $P$. betle leaf extract could either promote or inhibit melanogenesis due to the antioxidation property of $P$. betle leaf. The present study demonstrated that fresh PBE showed higher antioxidant activity and thus reduced the activity of tyrosinase and thereby inhibited excessive melanin production (antimelanogenic). Whereas, OPBE displayed lower antioxidant activity and thus enhanced the activity of tyrosinase and subsequently improved melanin production (promelanogenic). Therefore, PBE could be recommended for treating/avoiding both hypopigmentation and hyperpigmentation by varying the extract preparation. In addition, the precise mechanism of pro and antimelanogenesis effect should be explored in the future.

\section{Acknowledgements:}

The present study was funded by Chung Shan Medical University (CSMU-358294). The authors wish to thank the botanist Dr. Chun Wang, Chung Shan Medical University, Taiwan for authenticating the plant material.

\section{Conflict of interest:}

No conflict of interest to disclose for this study.

\section{REFERENCES}

1. Tsai TF. Pigmentation disorders in Taiwanese skin: a clinical experience. Int J Cosmet Sci 2005;27(1):54-6.

2. Valipour E, Arikan B. Increased production of tyrosinase from Bacillus megaterium strain M36 by the response surface method. Arch Biol Sci 2016;68(3):659-68.

3. Liang YR, Kang S, Deng L, Xiang LP, Zheng XQ. Inhibitory effects of (-)-epigallocatechin-3-gallate on melanogenesis in ultraviolet A-induced B16 murine melanoma cell. Trop J Pharm Res 2014;13(11):1825-31.

4. Jennifer C, Stephie CM, Abhishri SB, Shalini BU. A review on skin whitening property of plant extracts. Int J Pharm BioSci 2012;3(4):332-47.

5. Afaq F, Katiyar SK. Polyphenols: skin photoprotection and inhibition of photocarcinogenesis. Mini Rev Med Chem 2011;11(14):1200-15.

6. Nair R, Chanda S. Antimicrobial activity of Terminalia catappa, Manilkara zapota and Piper betel leaf extract. Indian J Pharm Sci 2008;70(3):390-93.

7. Rai MP, Thilakchand KR, Palatty PL, Rao P, Rao S, Bhat HP, et al. Piper betel Linn (betel vine), the maligned Southeast Asian medicinal plant possesses cancer preventive effects: Time to reconsider the wronged opinion. Asian Pac J Cancer Prev 2011;12(9):2149-56.

8. Thirumalai T, Tamilselvan N, David E. Hypolipidemic activity of Piper betel in high fat diet induced hyperlipidemic rat. J Acute Dis 2014;3(2):131-5.

9. Taukoorah U, Lall N, Mahomoodally F. Piper betle L.(betel quid) shows bacteriostatic, additive, and synergistic antimicrobial action when combined with conventional antibiotics. S Afr J Bot 2016;105:133-40. 
10. Dwivedi V, Tripathi S. Review study on potential activity of Piper betle. J Pharmacogn Phytochem 2014;3(4):93-8.

11. Sriwiriyajan $S$, Ninpesh $T$, Sukpondma $Y$, Nasomyon $T$, Graidist P. Cytotoxicity screening of plants of genus Piper in breast cancer cell lines. Trop J Pharm Res 2014;13(6):921-8.

12. Fazal F, Mane PP, Rai MP, Thilakchand KR, Bhat HP, Kamble PS, et al. The phytochemistry, traditional uses and pharmacology of Piper betel. Linn (Betel Leaf): A pan-asiatic medicinal plant. Chin J Integr Med 2014;1:1-11.

13. Periyanayagam K, Jagadeesan M, Kavimani S, Vetriselvan T. Pharmacognostical and Phyto-physicochemical profile of the leaves of Piper betle L. var Pachaikodi (Piperaceae) Valuable assessment of its quality. Asian Pac J Trop Biomed 2012;2(2):S506-S510.

14. Tan YP, Chan EWC. Antioxidant, antityrosinase and antibacterial properties of fresh and processed leaves of Anacardium occidentale and Piper betle. Food Biosci 2014;6:17-23.

15. Liu HN, Liu TY, Chen CC, Lee DD, Chang YT. Insights into the mechanism of Piper betle leaf-induced contact leukomelanosis using C57BL/6 mice as the animal model and tyrosinase assays. Australas J Dermatol 2011;52(3):172-8.

16. Row LC, Ho JC. The antimicrobial activity, mosquito larvicidal activity, antioxidant property and tyrosinase inhibition of Piper betle. J Chin Chem Soc 2009;56(3):653-8.

17. Kojima S, Yamaguchi H, Morita K, Ueno Y. Inhibitory effect of sodium 5, 6-benzylidene ascorbate (SBA) on the elevation of melanin biosynthesis induced by ultraviolet-A (UV-A) light in cultured B-16 melanoma cells. Biol Pharma Bull 1995;18(8):1076-80.

18. Yagi A, Kanbara T, Morinobu N. Inhibition of mushroomtyrosinase by aloe extract. Planta Med 1987;53(06):515-7.

19. Rosenthal MH, Kreider JW, Shiman R. Quantitative assay of melanin in melanoma cells in culture and in tumors. Anal Biochem 1973;56(1):91-9.

20. Bhattacharya S, Subramanian M, Roychowdhury S, Bauri
AK, Kamat JP, Chattopadhyay S, et al. Radioprotective property of the ethanolic extract of Piper betel leaf. J Radiat Res 2005;46(2):165-71.

21. Mula S, Banerjee D, Patro BS, Bhattacharya S, Barik A, Bandyopadhyay SK, et al. Inhibitory property of the Piper betel phenolics against photosensitization-induced biological damages. Bioorg Med Chem 2008;16(6):2932-8.

22. Pérez-Sánchez A, Barrajón-Catalán E, Herranz-López M, Castillo J, Micol V. Lemon balm extract (Melissa officinalis, L.) promotes melanogenesis and prevents UVB-induced oxidative stress and DNA damage in a skin cell model. J Dermatol Sci 2016;84(2):169-77.

23. Xiao L, Matsubayashi K, Miwa N. Inhibitory effect of the water-soluble polymer-wrapped derivative of fullerene on UVA-induced melanogenesis via downregulation of tyrosinase expression in human melanocytes and skin tissues. Arch Dermatol Res 2007;299(5-6):245-57.

24. Pradhan D, Suri KA, Pradhan DK, Biswasroy P. Golden heart of the nature: Piper betle L. J Pharmacog Phytochem 2013;1(6);147-67.

25. Bhattacharya S, Mula S, Gamre S, Kamat JP, Bandyopadhyay SK, Chattopadhyay S. Inhibitory property of Piper betel extract against photosensitization-induced damages to lipids and proteins. Food Chem 2007;100:1474.

26. Sim MO, Choi IY, Cho JH, Shin HM, Cho HW. Antimelanogenesis and anti-oxidant of Salix pseudo-lasiogyne water extract in $\alpha$-MSH-induced B16F10 melanoma cells. Food Agric Immunol 2017;13:1-4.

27. Hwang YS, Kim YJ, Kim MO, Kang M, Oh SW, Nho YH, et al. Cannabidiol upregulates melanogenesis through CB1 dependent pathway by activating p38 MAPK and p42/44 MAPK. Chem Biol Intract 2017;273:107-14.

28. Nair SS, Kavrekar V, Mishra A. In vitro studies on alpha amylase and alpha glucosidase inhibitory activities of selected plant extracts. Eur J Exp Biol 2013;3(1):128-32. 